\title{
Pulmonary functionality among workers of a Central Italy waste-to-energy plant: a retrospective study
}

\author{
L. Coppeta ${ }^{1 *}$ (D) A. Pietroiusti ${ }^{2}$, S. Policardo ${ }^{1}$, F. Mormone ${ }^{1}$, O. Balbi ${ }^{1}$, E. Tursi ${ }^{1}$, S. Baldi ${ }^{1}$, E. Plutoni ${ }^{1}$, A. Torriero ${ }^{2}$ and \\ A. Magrini ${ }^{2}$
}

\begin{abstract}
Background: We are observing a growing trend towards the use of waste incineration in waste-to-energy (WTE) plants in Italy. Various authors started to investigate their potential health effects, but without univocal outcomes. The aim of this study is to assess whether or not main pulmonary function indexes could be decreased in a group of workers employed in a municipal solid WTE plant located in Central Italy, and if there's a correlation between the levels of exposure to airborne pollutants and alterations in the pulmonary apparatus.

Methods: The study was conducted with a retrospective cohort approach. We reviewed data from clinical records of 58 waste-to-energy plant workers undergoing annual health surveillance in the period 2010-2015. We considered the exposure to airborne dust and the main parameters of respiratory function (FVC, FEV1, Tiffeneau Index and FEF $25-75 \%)$ at time zero and after a period of 5 years. We divided our study population into two groups: low (<1 mg/m3) and high (> $1 \mathrm{mg} / \mathrm{m} 3)$ exposure. We estimated odds ratios (OR) with $95 \%$ confidence interval $(95 \% \mathrm{Cl})$ adjusted for potential confounders.
\end{abstract}

Results: We observed a decrease in lung function parameters both in high and in low exposure group after a fiveyears exposure period. FEV1, FEV1/NC ratio and FEF 25-75\% were worst in more exposed group, even if this difference resulted not significant at Wilcoxon test.

Conclusions: Active employee in WTE plants is associated to a non-significant worsening in the main parameters of lung function after 5 years exposure. Clinical significant of these variations need to be assessed.

Keywords: Waste-to-energy, Industry-based, Retrospective cohort study, Waste incinerator, Pulmonary functionality, Spirometry, Respiratory function, Dust exposure

\section{Background}

Urban solid waste disposal has become a widely regarded issue nowadays and this led to an implementation of various strategies in order to reduce the quantities of material deposited in landfill sites. A growing trend towards the use of waste incineration in waste-to-energy (WTE) plants has been observed in Italy in the last 10 years.

Simultaneously, this phenomenon originated concerns on potential health effects caused by this kind of waste disposal procedure. Various studies in literature revealed

\footnotetext{
*Correspondence: Icoppeta@gmail.com

'Department of Occupational Medicine, University of Rome Tor Vergata,

Occupational Health Service, Viale Oxford 81, 00133 Rome, Italy

Full list of author information is available at the end of the article
}

an increased risk for pulmonary, neoplastic and other diseases, in both incinerator plant workers and resident population nearby the plant area $[1,3]$.

Regarding occupational risk, there are concerns about environmental contamination from particulate matter, bio-aerosol, heavy metals, toxic chemicals $(\mathrm{Be}, \mathrm{Cd}, \mathrm{Cr}$, $\mathrm{Pb}, \mathrm{Mn}, \mathrm{Hg}, \mathrm{Ni}$ and $\mathrm{V}$ ), and nanoparticles. In fact, the concentration of those substances is at particularly high levels in various areas of the plants. In published studies the levels of airborne dust ranged from 0.01 to $0.7 \mathrm{mg} /$ $\mathrm{m}^{3}[4]$.

In particular, while on the one hand environmental assessments suggest evidence of possible carcinogenic, mutagenic, reproductive and pulmonary effects of occupational 
exposure, on the other hand evidence reported by limited epidemiological studies is contradictory [1-6].

The main lung effects investigated among workers are respiratory symptoms and pulmonary function [5-13]. In particular, the presence of functional respiratory alterations attributable to the current levels of exposure is controversial.

The main limitations in assessing the association between risk and occupational exposure in WTE plants are represented by an inaccurate and heterogeneous evaluation of the exposure levels [9].

Therefore, despite the size of the problem, studies concerning the evaluation of possible health effects caused by occupational exposure in WTE plants are scarce and mostly inadequate experimentally [14].

\section{Methods}

Our study aimed to evaluate the pulmonary effects of exposure to airborne pollutants among a group of WTE workers employed in a central Italy plant, by investigating retrospectively the decrease in main pulmonary function indexes over a period of 5 years.

The initial study population consisted of 71 workers. We excluded data from 13 administrative employees without any exposure to airborne dust.

We finally included in the study records related to 58 male WTE workers who underwent annual medical screening in the period 2010-2015. The plant was located in the geographic area of Central Italy.

For privacy reasons, data were made anonymous through the insertion on two databases in Excel format, with an encrypted key available only to the investigators involved in the study. A database contained basic personal data (name and surname), while the other contained a personal code and all other variables, with the exception of first and last name.

People were considered eligible for the study if they had worked in the plant for almost 5 years. The exclusion criteria were the presence of systemic or immunological disorders, the presence of neoplasia, a previous diagnosis of asthma, emphysema, or interstitial lung disease [14].

At least three measurements of personal exposure to total dust were available during the examined period; the measurement was calculated as the mean level of exposure $(\mathrm{mg} / \mathrm{m} 3$ during $8 \mathrm{~h}$ of work).

Two levels of exposure were established a priori: low $(<1 \mathrm{mg} / \mathrm{m} 3)$ and high $(>1 \mathrm{mg} / \mathrm{m} 3)$. Those limits were chosen on the basis of current guidelines regarding the risk of respiratory disorders after occupational exposure to total dust $[15,16]$ : according to these guidelines, the threshold limit for generic dust is $10 \mathrm{mg} / \mathrm{m} 3$, and onetenth of the threshold limit is considered as the "attention level" beyond which adverse respiratory effects cannot be excluded.
Thoracic fraction (median size $11.6 \mu \mathrm{m}$ diameter) was considered in this study because it is the mass fraction that can reach the medium airways [17]. The level of the dust exposure was assessed by the gravimetric method, which is based on the collection of the thoracic fraction samples on filters made of poly-vinyl chloride at a flow rate of $2.2 \mathrm{l} / \mathrm{min}$.

Lung function test had been performed every year: we collected data from the first and the last year of the observation period (year 2010 and 2015 respectively).

All the workers enrolled in the study had performed a full ventilatory manoeuvre, both slow and forced acquisition of volume-time and flow-volume loop.

The measurement of lung volumes and flows had been assessed using a flow-based spirometer (SensorMedics, Vmax 20) according to the guidelines of the ATS (American Thoracic Society)-ERS (European Respiratory Society) 2005 workforce. At last, three consecutive acceptable trials had been performed for each subject [18].

From spirometry we collected the following parameters: Forced Vital Capacity (FVC); forced expiratory volume in the first second (FEV 1 or FEV); Tiffeneau Index (FEV1/VC); Peak Expiratory Flow (PEF); forced expiratory flow at $25 \%$ of FVC (FEF25\%); forced expiratory flow at 50\% of FVC (FEF50\%); forced expiratory flow at $75 \%$ of $\mathrm{FVC}$ (FEF75\%); forced expiratory flow between 25 and $75 \%$ of FVC (FEF25-75\%).

Decrease of lung function parameters after the 5 years period was recorded. Worsening in FEV1, FEV1/VC ratio (Tiffeneau Index) and in FEF $25-75 \%$ were considered as a possible dust exposure effect [19]. Decrease in lung function test was calculated both as quantitative and as dichotomous (yes or not) variable. All of the workers were investigated for main potentially confounding variables, such as age (more or less than 40 years old) and smoking habit. Gender influence was not evaluated since no female worker was employed in the plant.

No sample size study was conducted before and all eligible subjects were included in the study. The data were analyzed with STATA 11 statistical package. We used Chi Squared test for dichotomous variables and MannWhitney $\mathrm{U}$ test and Wilcoxon test for the continuous variables (FEV1, FVC, FEF25-75\%, FEV1/VC) since they showed non-normal distribution. Having a decline in FEV1/VC was the dependent variable of a binary logistic regression model, with age, smoking habits and dust exposure as independent variables [19].

The study was approved by the ethics committee of our institution.

\section{Results}

We analyzed data from 58 male WTE workers. Mean age was $46.7 \pm 8.0$ (range $35-59$ ) years. Mean exposure 
level (thoracic dust fraction) was $0.76 \pm 0.9$ (range 0.012.35) $\mathrm{mg} / \mathrm{m} 3$. According to our exposure criteria, 37 workers were classified as having low exposure and 21 as having high exposure. Mean seniority was $7.9 \pm 2.2$ years of employment. The main characteristics of the study population are shown in Table 1 .

Regarding the role of possible confounders, smokers were found with increased frequency among the lowexposure workers in comparison to those with high exposure $(57.7 \%$ versus $42.3 \%, \mathrm{p}=\mathrm{ns})$; also exposure was lower among workers with work seniority $>10$ years (57.4\% versus $42.6 \%$, with a significant $p=0.04$ ) and below the age of 40 ( $57.1 \%$ versus $42.9 \%, \mathrm{p}=\mathrm{ns})$.

While tested with Wilcoxon test, significant lowering in all of lung function parameters was observed both in high and in low exposure group after a five-years exposure period $(p<0.01)$. Fall in FEV1, FEV1/VC ratio and FEF $25-75 \%$ were higher in more exposed group even if this difference resulted not significant at Mann-Whitney U-test (Table 2).

Reduced value of FEV1/FVC was found in 12/58 (20.7\%) of study population after a 5 years period. A non-significant association between this parameter and level of exposure was found even considering the potential confounding role of smoking habit, age and seniority (Table 3).

[O.R. Odds Ratio, 95\% C.I. Confidence Interval]

\section{Discussion}

Lung function tests evaluation in the work setting should be part of a workplace respiratory health surveillance program among workers exposed to airborn dust [20]. Despite the community concerns about potential health effects of WTE plants, only few studies evaluated the lung function changes related to dust exposure among workers employed in those setting. Our study shows a decrease in airflow after a 5 years working period among WTE employees. The lowering in respiratory parameters was observed both in high and in low levels of exposure.

Since a physiological fall in lung function index was expected in the same period due to population ageing, the main result correlating with the possible effects of dust exposure is differential decrease between groups having different levels of exposure, despite this difference came out to be not significant at Wilcoxon test.

We observed a uniform trend to a worsening of all respiratory parameters in relation to the levels of exposure, including FEF25-75\%, that has been reported to be more sensitive than FEV1, and FEV1/VC ratio, in order to predict the development of clinically evident airflow obstruction associated with air pollution [21, 22] although their potential weakness is represented by its relatively high day-to-day variability [19].

Among our population smoking habit was related to higher risk of fall in FEV1/VC (although not statistically significant) suggesting a synergetic effect of exposure to dust and smoking.

Despite large epidemiological studies are lacking, results are partially consistent with the few published studies regarding the onset of airflow reduction in workers exposed to incinerator dust [19]. Bresnitz et al. [6] studied a cohort of 86 actively employed male workers of Philadelphia WTE plant; workers were divided into high and low exposure groups, and no statistically significant differences in main pulmonary function index were found between the two groups, whereas changes in pulmonary function were reported to be related only to smoking status. In a transversal study carried out for 102 male incinerator workers, a significant relationship

Table 1 Main characteristics of the study population

\begin{tabular}{|c|c|c|c|}
\hline & Low exposure & High exposure $_{b}$ & $p$ value $\left(x^{2}\right.$ test) \\
\hline Number (\%) & $37(63.8)$ & $21(36.2)$ & \\
\hline Exposure thoracic dust fraction $(\mathrm{mg} / \mathrm{m} 3)$ & 0.15 & 1.81 & \\
\hline Age (mean; yrs) & 47.5 & 45.4 & \\
\hline \multicolumn{4}{|l|}{ Age class } \\
\hline$<40$ years & $16(57.1)$ & $12(42.9)$ & \multirow[t]{2}{*}{0.31} \\
\hline$>40$ years & $21(70.0)$ & $3(30.0)$ & \\
\hline \multicolumn{4}{|l|}{ Work seniority } \\
\hline$<10$ years & $27(57.4)$ & $20(42.6)$ & \multirow[t]{2}{*}{0.04} \\
\hline$>10$ years & $10(90.9)$ & $1(9.1)$ & \\
\hline \multicolumn{4}{|l|}{ Smokers (\%) } \\
\hline Yes & $15(57.7)$ & $11(42.3)$ & \multirow[t]{2}{*}{0.38} \\
\hline Not & $22(68.7)$ & $10(31.3)$ & \\
\hline
\end{tabular}

a Defined as $<1 \mathrm{mg} / \mathrm{m3}$

${ }_{b}$ Defined as $>1 \mathrm{mg} / \mathrm{m} 3$ 
Table 2 Lung function parameters in low exposure and high exposure

\begin{tabular}{|c|c|c|c|c|c|c|}
\hline & Mean & Difference & S.D. & S.E. & 95\% C.I. & $p$ value \\
\hline FEV low exposure & 0.22 & -0.07 & 0.43 & 0.06 & $(0.13-0.35)$ & 0.34 \\
\hline FEV, high exposure (Liters) & 0.29 & & & & & \\
\hline FVC low exposure & 0.40 & -0.12 & 0.50 & 0.07 & $(0.32-0.58)$ & 0.65 \\
\hline FVC high exposure (Liters) & 0.52 & & & & & \\
\hline$F E V_{1} N C$ low exposure & 0.16 & -0.12 & 0.41 & 0.05 & $(0.10-0.31)$ & 0.93 \\
\hline FEV ${ }_{1}$ NC high exposure (Percentage) & 0.28 & & & & & \\
\hline$F E F_{25-75} \%$ low exposure & 0.19 & -0.05 & 0.41 & 0.05 & $(0.10-0.31)$ & 0.43 \\
\hline $\mathrm{FEF}_{25-75} \%$ high exposure (Liters) & 0.24 & & & & & \\
\hline
\end{tabular}

[S.D. Standard Deviation, S.E. Standard Error, 95\% C.I. Confidence Interval]

* Mann Whitney U Test

between exposure and the decrease of several pulmonary parameters was observed [5].

Taking in account differences in chemical composition of airborne dusts some data emerging from occupational cement dust exposure survey can be compared with results of our study. In a large prospective study conducted among cement workers increased odds ratios for symptoms and airflow limitation and $270 \mathrm{~mL}$ fall in FEV1 was observed in the highest quartile of exposure. Those results are consistent with the $285 \mathrm{~mL}$ decrease in FEV1 that we found in the high exposure group, but we failed to reach statistical significance. In an Italian study among 36 cement workers followed for 11 years, a decline of $340 \mathrm{~mL}$ in FEV1 was observed. This fall was equal to an annual decline of $31 \mathrm{~mL}$ [23]. In a study from former Yugoslavia, a significant decline in FEV1/ FVC was reported in an 8-year follow-up of a large group of cement workers.

In a recent review lung function tests have shown to be able to identify novel occupational respiratory diseases such as flavoring-related lung disease [24].

Possible limitations of our study are represented by the small size of our sample, the absence of a control group and by the selection mechanisms that may possibly have resulted in a healthy worker effect, commonly reported in previous studies regarding FEV1 and industrial exposure [5, 25].

The natural longitudinal lowering of lung function parameters may accelerate with increasing age [26, 27]. To evaluate a possible age effect, we tested between age > 40 years (yes/no), smoking habit and exposure in a

Table 3 Logistic regression analysis

\begin{tabular}{|c|c|c|c|c|}
\hline & \multicolumn{3}{|c|}{ Decline in FEV1NC } & \\
\hline & $O . R$ & 95\% C.I. & $p$ value & \\
\hline Smoking habit & 1.82 & $(0.49-6.85)$ & 0.37 & 0.89 \\
\hline Seniority $>10$ years & 2.39 & $(0.44-12.88)$ & 0.31 & 1.02 \\
\hline Age $>40$ years & 1.57 & $(0.41-6.01)$ & 0.51 & 0.66 \\
\hline High exposure & 2.67 & $(0.62-11.48)$ & 0.19 & 1.32 \\
\hline
\end{tabular}

multivariate analysis. The association remained negative after considering age and smoke confounding effect.

Another limitation of our study was that both low and high exposure workers were men, so the findings cannot be extrapolated for women. Waste incinerator dust exposure should be frequently found among women and it is possible that dust exposure in other occupational and extra-occupational settings may have different effects on lung function among women and younger subjects.

\section{Conclusions}

In our study, exposure to WTE plant airborne dust is associated to a non-significant worsening in the main parameters of lung function after 5 years exposure. These impairments are mild, according to ATS/ERS 2005 criteria [19], and the levels of airborne pollutants identified were constantly under the occupational threshold limit value. Clinical significant of these variations need to be assessed.

Further studies are necessary to confirm the findings of our study.

\section{Abbreviations}

ATS: American Thoracic Society; CIC: Confidence Interval; ERS: European Respiratory Society; FEF: Forced expiratory flow; FEV1: Forced expiratory volume in the first second; FVC: Forced Vital Capacity; OR: Odds ratios; PEF: Peak Expiratory Flow; VC: Vital Capacity; WTE: Waste-to-energy

\section{Authors' contributions}

LC, SP and FM analyzed and interpreted the patient data regarding the pulmonary function tests. AP and AM interpreted the results.ET, EP, OB and $\mathrm{SB}$ collected data of lung functions test. AT collected airborne dust exposure data. LC was a major contributor in writing the manuscript. All authors read and approved the final manuscript. There is no potential competing interest in our paper.

\section{Funding}

Not applicable.

\section{Availability of data and materials}

The datasets used and/or analyzed during the current study are available from the corresponding author on reasonable request.

\section{Ethics approval and consent to participate}

The study was approved by the ethics committee of our institution (Protocol Number 131/18). Written consent was obtained from all participants. 


\section{Consent for publication}

Not applicable

\section{Competing interests}

The authors declare that they have no competing interests

\section{Author details}

'Department of Occupational Medicine, University of Rome Tor Vergata, Occupational Health Service, Viale Oxford 81, 00133 Rome, Italy. ${ }^{2}$ Department of Biomedicine and Prevention, University of Rome Tor Vergata, Rome, Italy.

Received: 3 January 2019 Accepted: 25 June 2019

Published online: 04 July 2019

\section{References}

1. Porta D, Milani S, Lazzarino Al, Perucci CA, Forastiere F. Systematic review of epidemiological studies on health effects associated with management of solid waste. Environ Health. 2009 Dec 23;8:60. https://doi.org/10.1186/1476069X-8-60.

2. Hu SW, Shy CM. Health effects of waste incineration: a review of epidemiologic studies. J Air Waste Manag Assoc. 2001;51(7):1100-9 Review.

3. Golini MN, Ancona C, Badaloni C, Bolignano A, Bucci S, Sozzi R, Davoli M, Forastiere F. Morbidity in a population living close to urban waste incinerator plants in Lazio Region (Central Italy): a retrospective cohort study using a before-after design. Epidemiol Prev. 2014 Sep-Oct;38(5):323-34.

4. Tolvanen OK, Hänninen Kl. Mechanical-biological waste treatment and the associated occupational hygiene in Finland. Waste Manag. 2006;26(10): 1119-25 Epub 2005 Oct 5

5. Hours M, Anzivino-Viricel L, Maitre A, Perdrix A, Perrodin Y, Charbotel B, Bergeret A. Morbidity among municipal waste incinerator workers: a crosssectional study. Int Arch Occup Environ Health. 2003;76(6):467-72 Epub 2003 May 23.

6. Bresnitz EA, Roseman J, Becker D, Gracely E. Morbidity among municipal waste incinerator workers. Am J Ind Med. 1992;22(3):363-78.

7. Health effects of waste incineration: a review of epidemiologic studies. Hu SW, Shy CM. J Air Waste Manag Assoc. 2001 Jul;51(7):1100-9.

8. Charbotel B, Hours M, Perdrix A, Anzivino-Viricel L, Bergeret A. Respiratory function among waste incinerator workers. Int Arch Occup Environ Health. 2005;78(1):65-70 Epub 2004 Dec 15.

9. Sharma R, Sharma M, Sharma $R$, et al. The impact of incinerators on human health and environment. Rev Environ Health. 2013;28(1):67-72 Retrieved 27 Feb. 2018.

10. Cordioli M, Ranzi A, Giulio A, Leo D, Lauriola P. A Review of Exposure Assessment Methods in Epidemiological Studies on Incinerators. J Environ Public Health. 2013;2013, Article ID 129470:12.

11. Angerer J, Heinzow B, Reimann DO, Knorz W, Lehnert G. Internal exposure to organic substances in a municipal waste incinerator. Int Arch Occup Environ Health. 1992:64:265-73.

12. Boswell RT, McCunney RJ. Bronchiolitis obliterans from exposure to incinerator fly ash. J Occup Environ Med. 1995;37:850-5.

13. Shy CM, Degnan D, Fox DL, et al. Do Waste Incinerators Induce Adverse Respiratory Effects? An Air Quality and Epidemiological Study of Six Communities. Environ Health Perspect. 1995;103(7-8):714-24.

14. Siracusa A, Forcina A, Volpi R, et al. An 11-year longitudinal study of the occupational dust exposure and lung function of polyvinyl chloride, cement and asbestos cement factory workers. Scand J Work Environ Health. 1988;14:181-8.

15. ACGIH Threshold Limit Values for Chemical Substances (TLV $\left.{ }^{\oplus}-C S\right), 2006$

16. Sharma G, Goodwin J. Effect of aging on respiratory system physiology and immunology. Clin Interv Aging. 2006;1:253-60.

17. Comité Européen de Normalisation. Workplace Atmospheres - Size Fractions Definition Procedures for Measurement of Airborne Particles (EN 481). Brussels: CEN; 1993.

18. Wanger J, Clausen JL, Coates A, Pedersen OF, Brusasco V, Burgos F, Casaburi R, Crapo R, Enright P, van der Grinten CP, Gustafsson P, Hankinson J, Jensen R, Johnson D, Macintyre N, McKay R, Miller MR, Navajas D, Pellegrino R, Viegi G. Standardisation of the measurement of lung volumes. Eur Respir J. 2005 Sep;26(3):511-22.

19. Pellegrino R, Viegi $G$, Brusasco $V$, et al. Interpretative strategies for lung function tests. Eur Respir J. 2005;26(5):948-68 https://doi.org/10.1183/ 09031936.05.00035205] [PMID: 16264058].
20. Redlich CA, Tarlo SM, Hankinson JL, Townsend MC, Eschenbacher WL, Von Essen SG, Sigsgaard T, Weissman DN. American Thoracic Society Committee on Spirometry in the Occupational Setting. Official American Thoracic Society technical standards: spirometry in the occupational setting. Am J Respir Crit Care Med. 2014 Apr 15;189(8):983-93. https://doi.org/10.1164/ rccm.201402-0337ST].

21. Brown K, Sly PD, Milic-Emili J, Bates JH. Evaluation of the flow-volume loop as an intra-operative monitor of respiratory mechanics in infants. Pediatr Pulmonol. 1989;6(1):8-13.

22. Wilson TA, Fredberg JJ, Rodarte JR, Hyatt RE. Interdependence of regional expiratory flow. J Appl Physiol (1985). 1985 Dec;59(6):1924-8.

23. Nordby KC, Notø H, Eduard W, Skogstad M, Fell AK, Thomassen Y, Skare $\varnothing$, Bergamaschi A, Pietroiusti A, Abderhalden R, Kongerud J, Kjuus H. Thoracic dust exposure is associated with lung function decline in cement production workers. The European Respiratory Journal. 2016;48(2):331-9 Epub 2016 Apr 21

24. Redlich CA, Tarlo SM. Longitudinal assessment of lung function decline in the occupational setting. Curr Opin Allergy Clin Immunol. 2015 Apr;15(2): 145-9. https://doi.org/10.1097/ACl.0000000000000153].

25. Eisen EA, Wegman DH, Louis TA, Smith TJ, Peters JM. Healthy worker effect in a longitudinal study of one-second forced expiratory volume (FEV1) and chronic exposure to granite dust. Int J Epidemiol. 1995;24:1154-61.

26. $L i C Y$, Sung FC. A review of the healthy worker effect in occupational epidemiology. Occup Med (Lond). 1999;49:225-9.

27. Hnizdo E, Sircar K, Glindmeyer HW, et al. Longitudinal limits of normal decline in lung function in an individual. J Occup Environ Med. 2006; 48:625-34.

\section{Publisher's Note}

Springer Nature remains neutral with regard to jurisdictional claims in published maps and institutional affiliations.
Ready to submit your research? Choose BMC and benefit from:

- fast, convenient online submission

- thorough peer review by experienced researchers in your field

- rapid publication on acceptance

- support for research data, including large and complex data types

- gold Open Access which fosters wider collaboration and increased citations

- maximum visibility for your research: over $100 \mathrm{M}$ website views per year

At $\mathrm{BMC}$, research is always in progress.

Learn more biomedcentral.com/submissions 